\title{
Sand colour at Cuba and its influence on beach nourishment and management
}

Enzo Pranzini, Giorgio Anfuso, Camilo Mateo Botero, Alfredo Cabrera, Yanet Apin Campos, Grace Casas Martinez, Allan T. Williams.

\begin{abstract}
The colour of 93 beaches in Cuba was assessed in CIEL ${ }^{*}{ }^{*} b^{*}$ colour space. Study sites comprised exposed and sheltered mainland beaches and keys. Notwithstanding the limited extension of this country, beaches show real colour variability due to mineralogical differences in rock outcrops in the various watersheds, the proximity of the coral reef and the shell fragments originated in open coast or mangrove areas. PCA performed on the $L^{*}$, $a^{*}$ and $b^{*}$ parameters allowed beach groupings which fitted with their geographical locations and identified those altered by beach nourishment. Sand lightness was considered by taking into account visitor's preferences, addressed to very clear sand, which is infrequent in mainland Cuba. One strongly coloured beach was found, for which a geosite institution is proposed. The impact of beach nourishment on native sand colour was studied and the beach at Varadero, probably the most popular Cuban beach, was negatively impacted by this activity. Reconstruction was necessary after severe erosion induced by Sea Level Rise and hurricanes. Recommendations for wise beach nourishment in tropical areas are given.
\end{abstract}

\section{Keywords}

a, b, Beach nourishment, Beaches, CIEL, Sand color, Tourism 